\title{
Family Resource Allocation after Firstborns Leave Home: Implications for Secondborns' Academic Functioning
}

Alexander C. Jensen PhD

Brigham Young University, alexjensen@byu.edu

Shawn D. Whiteman

Julia M. Bernard

Susan M. McHale

Follow this and additional works at: https://scholarsarchive.byu.edu/facpub

Part of the Psychology Commons

\section{Original Publication Citation}

Jensen, A. C., Whiteman, S. D., Bernard, J. M., \& McHale, S. M. (2017). Resource reallocation?

Implications of parents' resource distribution following firstborns' leaving home. Family

Process, 56, 766-780. doi:10.1111/famp.12203

\section{BYU ScholarsArchive Citation}

Jensen, Alexander C. PhD; Whiteman, Shawn D.; Bernard, Julia M.; and McHale, Susan M., "Family Resource Allocation after Firstborns Leave Home: Implications for Secondborns' Academic Functioning" (2017). Faculty Publications. 3524.

https://scholarsarchive.byu.edu/facpub/3524

This Peer-Reviewed Article is brought to you for free and open access by BYU ScholarsArchive. It has been accepted for inclusion in Faculty Publications by an authorized administrator of BYU ScholarsArchive. For more information, please contact ellen_amatangelo@byu.edu. 


\title{
Family Resource Allocation after Firstborns Leave Home: Implications for Secondborns' Academic Functioning
}

\author{
ALEXANDER C. JENSEN* \\ SHAWN D. WHITEMAN \\ JULIA M. BERNARD: \\ SUSAN M. MCHALE
}

This study assessed secondborn adolescents' perceptions of changes in the allocation of family resources following their firstborn siblings' departure from home after high school, and whether perceived changes were related to changes over 1 year in secondborns' academic functioning. Participants were secondborn siblings (mean age $=16.58, \mathrm{SD}=0.91$ ) from 115 families in which the older sibling had left the family home in the previous year. Allocation of resources was measured via coded qualitative interviews. Most (77\%) secondborns reported increases in at least one type of family resource (i.e., parental companionship, attention, material goods), and many reported an increase in multiple types of resources in the year following their older sibling's departure. Consistent with resource dilution theory, perceptions of increases in fathers' companionship, fathers' attention, and mothers' companionship were related to improvements over time in secondborns' academic functioning.

Keywords: Academic achievement; Family process; Family resources; Family transitions; Parent-adolescent relationships ; Resource dilution; Siblings

Fam Proc $x: 1-15,2015$

$\mathrm{F}$ amily social and material resources play a critical role in youth educational achievement (Coleman, 1988; Davis-Kean, 2005): When children receive more family resources-including parental time and attention - they exhibit better academic functioning and higher attainment (Christenson, Rounds, \& Gorney, 1992; Davis-Kean, 2005; Okagaki \& Frensch, 1998). A range of factors can affect the extent of family resources, including parents' income and education (Davis-Kean, 2005; Parker, Boak, Griffin, Ripple, \& Peay, 1999), but the distribution of resources within families is shaped, at least in part, by the number and characteristics of offspring. According to resource dilution theory, because family resources are finite, children in larger families receive fewer resources, on average, than those from smaller families. In turn, diminished resources are expected to lead to lower levels of achievement in children from larger families (Behrman, Pollak, \& Taubman, 1989; Blake, 1989; Downey, 2001; Lawson \& Mace, 2008; Steelman, Powell, Werum, \& Carter, 2002). Despite some evidence linking sibship size to academic

\footnotetext{
*School of Family Life, Brigham Young University, Provo, UT.

${ }^{\dagger}$ Human Development and Family Studies, Purdue University, West Lafayette, IN.

${ }^{\ddagger}$ East Tennessee State University, Johnson City, TN.

${ }^{\S}$ Human Development and Family Studies, The Pennsylvania State University, University Park, PA.

Correspondence concerning this article should be addressed to Alexander C. Jensen, School of Family Life, Brigham Young University, 2086 JFSB, Provo, UT, 84602. E-mail: alexjensen@byu.edu
} 
functioning, the mechanisms underlying siblings' academic outcomes (i.e., the dilution of resources) have rarely been measured directly (Downey, 2001). To advance understanding of the role of sibship size in the distribution of resources, this study took advantage of a "natural experiment", a change in household size brought about by firstborns' leaving home after high school, to assess whether this family transition had implications for adolescent secondborns' resources and in turn, whether perceived increases in family resources were linked to improvements over 1 year in secondborns' academic functioning.

\section{THE ALLOCATION OF FAMILY RESOURCES}

A tenet of resource dilution theory is that children in larger sibships have access to fewer family resources compared to those with fewer siblings. As noted by several scholars (Blake, 1989; Downey, 1995; Rodgers, Cleveland, van den Oord, \& Rowe, 2000), the link between sibship size and youths' access to family resources may be confounded by a range of factors that may account for both sibship size and the allocation of family resources (Ernst \& Angst, 1983; Retherford \& Sewell, 1989; Rodgers et al., 2000). In an attempt to address this issue and account for possible selection effects, Downey (1995) found that after controlling for family income, parent education, parent occupation, and family structure, those from larger families tended to receive less parental companionship, parental attention, and fewer material resources (access to books and educational materials) than those from smaller sibships. As noted by Rodgers et al. (2000), however, the processes that shape which parents have more children and which have fewer (i.e., culture, religion, ethnicity, intelligence) are incredibly complex and difficult to completely account for analytically. Thus, a myriad of potential selection effects limit what can be gleaned from crosssectional analyses linking sibship size and family resources.

A within-person design-wherein individuals are treated as their own controls-accounts for the possible selection effects that could explain the inverse link between sibship size and the allocation of family resources. Although not aimed at testing resource dilution theory, early research on the transition to siblinghood took advantage of a within-person approach to examine the experiences of a firstborn child following the birth of a sibling (Gottlieb \& Mendelson, 1990; Kendrick \& Dunn, 1980; Stewart, 1990). Findings from this literature are consistent with resource dilution theory in showing that both maternal companionship and attention toward firstborns declined when sibship size increased from before to after the birth of a secondborn sibling (Lasko, 1954; Strohschein, Gauthier, Campbell, \& Kleparchuk, 2008; Volling, 2012).

In the course of family development, another point in time when sibship size effectively changes is when siblings approach adulthood and begin to leave home. In contrast to the increase in sibship size brought about by the birth of a sibling, a sibling leaving home may be experienced as a decrease in sibship size in the everyday lives of families. Indeed, recent work suggests that family patterns and relationships adjust when older offspring leave home (Whiteman, McHale, \& Crouter, 2011). It is possible that adjustments also occur in regard to the allocation of family resources. Thus, to better understand the role of sibship size in the allocation of family resources, in the present study we took advantage of this "natural experiment" in family life to examine secondborns' perceptions of changes in the allocation of family resources during the year after their older sibling graduated high school and moved away from home. Following the work of Downey (1995), we examined three categories of family resources: (a) parent-child companionship; (b) parental attention devoted to offspring; and (c) access to material goods. Based on resource dilution theory, we predicted that secondborns would report increases in family resources in the year following their siblings' departures. 


\section{CHANGING FAMILY RESOURCES AND CHANGES IN ACADEMIC FUNCTIONING}

A second tenet of resource dilution theory is that sibship size has its effects on academic achievement via its effects on the distribution of family resources (Blake, 1989; Conley, Pfeiffer, \& Velez, 2007; Steelman et al., 2002). As noted, most support for this idea comes from studies that compare the academic achievement of children who grow up in smaller families with that of children who grow up in larger families (Conley et al., 2007; Downey, 1995; Steelman et al., 2002). Studies based on such between-family comparisons have been criticized, however, because they often fail to account for third variables - for instance, parent characteristics - that may explain both sibship size and youth academic achievement. Other studies have used within-family designs to compare children from the same family as a function of birth order based on the rationale that, because later born siblings, on average, experience fewer (i.e., more diluted) family resources than their earlier born siblings, later born siblings should have poorer academic functioning. In contrast to between-family comparisons as a function of sibship size, findings from within-family comparisons of youth academic achievement as a function of birth order reveal little support for resource dilution theory (Berbaum \& Moreland, 1980; Rodgers et al., 2000).

In an effort to provide insights into the ongoing debate about the role of sibship size in family resource allocation and academic achievement, in this study we took a new tack, examining whether changes in youths' resources brought about by their older siblings' leaving home explained changes over time in youths' academic achievement. In other words, taking advantage of the power of within-person comparison design, we tested whether changes in the number of siblings in the home spurred increases in youths' resources, and in turn, improvements in youths' academic functioning. Across the adolescent years, academic functioning, including school grades and academic interests, tends to decline (Barber \& Olsen, 2004; Dotterer, McHale, \& Crouter, 2009). Thus, findings that increases in resources brought about by a sibling's departure correspond to improvements over time in youths' academic functioning may provide evidence of the significance of sibling-related family resource allocations in youths' academic achievement.

\section{CURRENT STUDY}

In sum, the aims of this study were to assess secondborns' perceptions of changes in their family resources during the year after their firstborn siblings graduated from high school and left home and to test whether increases in family resources were linked to improvements in secondborns' academic functioning over time. Following Downey (1995), we focused on both relational and material resources, including mother-child companionship, father-child companionship, maternal attention, paternal attention, and access to material goods. Based on the tenets of resource dilution theory regarding sibship size (Downey, 1995, 2001), we expected that secondborns would report increases in access to these resources in the year following their siblings' departure. Further, we predicted that increases in secondborns' resources would be associated with improvements over the year in their academic functioning, indexed by school grades and self-rated interest in academics. Given the gendered nature of family dynamics (Raley \& Bianchi, 2006), we controlled for secondborns' gender in all analyses. To account for between-family variations in resources, we also controlled for parental education.

\section{METHOD}

\section{Participants}

Data were drawn from a longitudinal study on family relationships that followed families through the year following firstborns' completion of high school. Participants in the

Fam. Proc., Vol. x, $x x x x, 2015$ 
larger study included mothers, fathers, and their firstborn and secondborn offspring from 201 dual-earner, working/middle class ( $M$ family income $=\$ 78,640, S D=\$ 40,188 ; M d n$ family income $=\$ 77,000)$, married parent families $(93 \%)$ who resided in small towns, cities, and rural areas of a northeastern state. All families were Caucasian. Although the sample is not representative of U.S. families in general, it comes close to capturing the racial background of the families from the region where the data were collected (>94\% White). Families were, however, more affluent than state estimates (Mdn family income $=\$ 52,548$; U.S. Census Bureau, 2015), likely reflecting that the current sample included maritally intact, mostly dual-earner families.

Given the goals of the current analyses, data collected during the year before and the year after the firstborns' high school graduation were used, and the sample was restricted to families in which the firstborn had moved out of the family home following the completion of high school $(n=115)$. Firstborns were treated as having left home if they primarily resided outside of their parents' home (defined as four or more nights per week away from home) during the past academic year. Of the firstborns who left home, $91 \%$ went to college. Secondborns $(51.6 \%$ girls) averaged 16.58 years of age $(S D=0.91)$, were on average 2.51 $(S D=0.82)$ years younger than their firstborn siblings, and just under half $(47 \%)$ were the same gender as their older sibling. The majority of families had two offspring (55.7\%), $34.8 \%$ had three, $6.1 \%$ had four, and $3.5 \%$ had five offspring. This leaving home $(n=115)$ subsample did not differ from the 86 families who were excluded on any individual or family demographic variable or on school interest, but secondborns from the subsample had higher GPAs $(M=3.35, S D=.76)$ than did secondborns whose older sibling did not leave home after high school graduation $(M=3.04, S D=.76), F(1,190)=7.81, p<.01$.

\section{Procedure}

For the purposes of this study, we used data from two phases of data collection: the years before and after firstborns' high school graduation. During each phase, home interviews were conducted to collect information on family members' personal characteristics and youths' academic outcomes. Mothers, fathers, and secondborns were interviewed separately during the spring, which allowed for changes in household size, family dynamics, and youth academic functioning to become established across the year after firstborns' high school graduations. Data for the present study come primarily from the youth interview, as parent interviews did not focus on issues explicitly related to the present study. Interview duration averaged one hour for youth and 2-3 hours for parents. Informed consent/assent was obtained from each family member, and the family received an honorarium of $\$ 200$ depending at each phase. The institutional review board approved all procedures.

\section{Measures}

\section{Demographic information}

Data on offspring characteristics (e.g., age and gender), firstborns' household residence, and household size were obtained from parents at the start of the home interview. Household size following the departure of the firstborn was dummy coded $(0=$ one child remained after firstborn left home, 1 = more than one child remained after firstborn left home).

\section{Changes in secondborns' family resources}

During the home interview, secondborns whose older sibling was no longer living at home were asked three open-ended questions: "In some families, having the oldest child [leave home/go to college] makes a big difference, but for other families there isn't much 
change. Can you tell me how your relationship with your mom/dad has changed since [sibling] is no longer living at home?" "What is the best thing for you about [sibling] leaving home with respect to your relationship with your mom/dad?" What is the worst thing for you about [sibling] leaving home with respect to your relationship with your mom/dad?" Youths' answers to these questions were audio-recorded and later transcribed for coding.

Based on the family relationships and resource dilution theory literatures (Blake, 1989; Downey, 1995), three a priori chosen categories, parent-child companionship (maternal and paternal), parental attention (maternal and paternal), and material resources (not parent specific), were coded. Two graduate and one undergraduate research assistant served as coders, and all three coded each transcript. All three coders were blind to the study hypotheses. Coders reviewed the transcripts to determine whether the sibling reported a change in one of the target domains. If a change was reported, the coders then recorded the direction of the change (i.e., increased or decreased). If a domain was not mentioned, a code of no change was given. Change was coded when at least two of three coders agreed on the absence or presence and direction of change.

\section{Changes in parent-child companionship}

This category focused on reports of changes in hanging out together, talking and interacting, and spending time in activities with a parent. Examples included the following: "We also talk more and we do more things together; play games, or we work together just cleaning the house and stuff", and "We seem to spend more time together now". Cohen's $\kappa$ for inter-rater reliability was .65 for mothers and .86 for fathers.

\section{Changes in parental attention}

This category included parents' focus, pressure, surveillance, and other kinds of attention, for example, "She's been paying more attention to me, school, school work, what I'm doing. Uh, it's kind of odd to be under the more watching eye. Umm, yea the ... more of the focus has been shifted to me"; "[He] spends more time watching what I do." Cohen's $\kappa$ for inter-rater reliability was .71 mothers and .78 for fathers.

\section{Changes in material goods}

These changes included both receiving and having greater access to material resources, for example, "No one is hogging the computer, so I have time to do my homework", and "Well, the piano is open more, the computer is open more, the things we both like to dothere's more time to do them because she's not here to use them as often." Cohen's $\kappa$ was .61 .

\section{Changes in academic functioning}

Two measures of academic functioning were assessed in the years prior to and following the firstborn's departure.

\section{Academic performance}

Academic performance was assessed in terms of school grades, which were collected from report cards obtained during the parent interviews. Given the range in youths' coursework, we focused on two subjects that most youth had studied, math and language arts. Grades were scored on a 5-point scale $(0=F-4=\mathrm{A})$. Secondborns' grades averaged in the B to B+ range for both subjects both before (math: $M=3.08, S D=1.00$; language arts: $M=3.25, S D=.94$ ) and after (math: $M=3.17, S D=.95$; language arts: $M=3.35$, $S D=.79)$ the departure of their older sibling.

Academic interests

Academic interests were assessed for the subjects of math and language arts (Dotterer et al., 2009; Huston, McHale, \& Crouter, 1985). Youth were asked, "How interested are 
you in math/language arts?" and responded on a 4-point scale that ranged from 1 (not at all) to 4 (very interested). On average, secondborns reported moderate interest in math and language arts both before (math: $M=2.42, S D=1.03$; language arts: $M=2.43$, $S D=1.07$ ) and after (math: $M=2.38, S D=1.03$; language arts: $M=2.41, S D=.97$ ) the departure of their older sibling.

\section{Analytic Strategy}

We first examined patterns of missing data and discovered that several cases were missing data on either dependent or independent variables ( $M$ percent missing per variable $=3.40 \%, S D=3.36 \%$ ). Results of Little's MCAR test suggested that data were missing completely at random $\left(\chi^{2}=101.00, d f=96, p=.34\right)$. To account for the missing data, we used the multiple imputation method in SPSS 21 by creating 5 imputed data sets and then pooling variables across the data sets.

In order to address our aims, we employed two different analytic strategies. First, we present descriptive data and cross-tabulations of resource categories to capture secondborns' perceptions of how their access to different types of resources changed following their older siblings' departure from the family home. Second, to examine the relation between changes in resources (given the rarity of reports of declines we focused only on increases) and secondborns' academic functioning, we conducted a series of repeated-measures analyses of covariance (R-ANCOVAs). These models tested for both the between-person effect of resource change (no increase vs. increase) and the within-person effect of time (before vs. after firstborns left home). Covariates were sibship size ( $0=2$ siblings; $1=3$ or more siblings), secondborns' gender $(0=$ female; $1=$ male), age during the year prior to the firstborn's leaving home, and maternal and paternal education. We tested all two-way interactions involving the time factor. A significant resource change $\times$ time effect indicated that there was a (as predicted) difference between youth who experienced a resource increase versus those who did not in the extent of change over time in academic functioning. A power analysis using Proc GLMPower in SAS revealed that power for these models never rose above .56, well below the standard .80 (Cohen, 1988). Thus, we limited our testing of interactions to only those between each covariate and time, and did not include higher order interactions in the models.

\section{RESULTS}

\section{Changes in Resources}

We first examined changes in resources reported by secondborns. Table 1 presents the numbers (and percentages) of youths who reported changes (decreases and increases) in resources in each domain. With respect to parent-child relationships, more than a third perceived an increase in maternal companionship, about a third reported an increase in paternal companionship, a little under half perceived an increase in maternal attention, a little less than a third reported an increase in paternal attention, and about a quarter reported an increase in material resources. Less than $2 \%(n=4)$ of secondborns reported decreases in any category of resource following their older siblings' departures. There were no associations between secondborns' gender and increases in any resource category.

We also examined the number of domains in which youth reported changes, focusing on increases in resources given the rarity of reports of resource declines. Cross-tabulations revealed that $30(26 \%)$ reported an increase in one resource only; 35 (30\%) reported an increase in two resources; $15(13 \%)$ reported an increase in three resources; 6 (5\%) reported an increase in four resources; and 3 (3\%) reported an increase in each of the five 
TABLE 1

Numbers (and percentages) of Secondborns Who Reported Decreases, Increases, and Who did not Report

Change in Parental and Family Resources in the Year Following their Firstborn Siblings' Leaving Home

$(\mathrm{N}=115)$

\begin{tabular}{lccc}
\hline Domain & Decrease & No reported change & Increase \\
\hline Companionship & & & \\
Mother & $2(1.74)$ & $72(62.61)$ & $41(35.65)$ \\
Father & $1(0.87)$ & $75(65.22)$ & $39(33.91)$ \\
Attention & & & \\
Mother & $0(0.00)$ & $69(60.00)$ & $46(40.00)$ \\
Father & $0(0.00)$ & $80(69.57)$ & $35(30.43)$ \\
Material goods & $1(0.86)$ & $86(74.78)$ & $28(24.35)$ \\
\hline
\end{tabular}

resources. Thus, across all types of resources, 89 (77\%) secondborns reported an increase in at least one type of resource.

\section{Implications of Changing Parental Resources for GPA and Academic Interest}

\section{Math and language arts grades}

The model for math grades (Table 2) revealed a between-groups effect of sibship size, $F$ $(1,103)=4.46, p<.05$, such that those with only one other sibling $(M=2.96, S D=1.09)$ received lower grades on average than did those with more siblings $(M=3.32, S D=1.13$; $d=.32$ ). A between-groups effect of maternal attention, $F(1,103)=3.92, p<.05$, also revealed that those who did not report an increase in attention $(M=3.33, S D=1.37)$ received higher grades on average than did those who did report an increase in attention $(M=2.95, S D=0.98 ; d=.32)$. Several within-groups effects also emerged. Specifically, an overall effect of time, $F(1,103)=5.29, p<.05$, suggested that youth exhibited a small increase in math grades from the year prior $(M=3.08, S D=1.00)$ to the year after $(M=3.17, S D=.95$; Cohen's $d=.09)$ their older sibling left home. A time $\times$ paternal companionship change effect, $F(1,103)=4.02, p<.05$ (Figure 1 ), revealed that youth who did not report an increase in companionship with their father did not change in their math performance from the year prior $(M=3.00, S D=1.22)$ to the year following $(M=2.94$, $S D=1.11 ; d=.05)$ their older sibling's departure. In contrast, those who reported an increase in paternal companionship exhibited an increase in their math grades from before $(M=3.11, S D=1.04)$ to after $(M=3.41, S D=.95 ; d=.30)$ their sibling left home. Results also revealed a time $\times$ gender effect, $F(1,103)=4.77, p<.05$. Girls increased in math grades from the year prior $(M=3.12, S D=1.09)$ to the year after $(M=3.38$, $S D=.99 ; d=.25$ ), whereas boys' math grades, on average, did not change (year prior: $M=3.05, S D=1.16$; Year after: $M=2.98, S D=1.06 ; d=.06$ ).

In terms of language arts grades (Table 2), a significant between-groups effect of gender, $F(1,103)=11.58, p<.001$, revealed that girls $(M=3.52, S D=.91)$ received higher grades on average than did boys $(M=3.09, S D=.96 ; d=.46)$. A between-groups effect of sibship size, $F(1,103)=6.89, p<.01$, also revealed that those with only one sibling $(M=3.11, S D=.95)$ received lower grades on average than did those with more than one sibling $(M=3.49, S D=.99 ; d=.39)$.

\section{Math and language arts interests}

Turning to interest in math (Table 3 ), the analysis revealed a significant time $\times$ paternal attention change effect, $F(1,103)=4.26, p<.05$ (Figure 2): As hypothesized, youth who did not report an increase in paternal attention declined in math interest from the 
TABLE 2

Repeated-measures Analysis of Covariance for Between- and Within-Person Effects for Two Models, Youths' Math Grades (n = 115) and Language Arts Grades (n = 115)

\begin{tabular}{|c|c|c|c|c|}
\hline \multirow[b]{2}{*}{ Source } & \multicolumn{2}{|c|}{ Math grades } & \multicolumn{2}{|c|}{ Language arts grades } \\
\hline & Mean square & $F$ value & Mean square & $F$ value \\
\hline \multicolumn{5}{|l|}{ Between-person effects } \\
\hline Gender & 3.07 & 2.40 & 10.08 & $11.58 * * *$ \\
\hline Age & 2.46 & 1.92 & .00 & .00 \\
\hline Mother education & .93 & .73 & .00 & .00 \\
\hline Father education & .94 & .74 & 2.72 & 3.12 \\
\hline Sibship size & 5.71 & $4.46^{*}$ & 5.99 & $6.89 * *$ \\
\hline Mother companionship & .12 & .09 & .02 & .02 \\
\hline Mother attention & 5.02 & $3.92 *$ & .92 & 1.05 \\
\hline Father companionship & 4.05 & 3.17 & 1.27 & 1.46 \\
\hline Father attention & .85 & .67 & .02 & .02 \\
\hline Material goods & 1.44 & 1.12 & .43 & .49 \\
\hline Error & 1.28 & & .87 & \\
\hline \multicolumn{5}{|l|}{ Within-person effects } \\
\hline Time & 1.67 & $5.29 *$ & .00 & .01 \\
\hline Time $\times$ Gender & 1.51 & $4.77^{*}$ & .97 & 2.81 \\
\hline Time $\times$ Age & .24 & .75 & .61 & 1.75 \\
\hline Time $\times$ Mother education & .69 & 2.18 & .70 & 2.02 \\
\hline Time $\times$ Father education & .22 & .68 & .89 & 2.59 \\
\hline Time $\times$ Sibship size & .90 & 2.85 & .49 & 1.42 \\
\hline Time $\times$ Mother companionship & .05 & .16 & .00 & .01 \\
\hline Time $\times$ Mother attention & .00 & .00 & 1.26 & 3.64 \\
\hline Time $\times$ Father companionship & 1.27 & $4.02 *$ & .02 & .05 \\
\hline Time $\times$ Father attention & .91 & 2.87 & .00 & .00 \\
\hline Time $\times$ Material goods & .07 & .22 & .09 & .26 \\
\hline Error & .32 & & .35 & \\
\hline
\end{tabular}

${ }^{*} p<.05 .{ }^{* *} p<.01 .{ }^{* *} p<.001$.

year prior $(M=2.38, S D=1.28)$ to the year after $(M=2.23, S D=1.24 ; d=.12)$ their older sibling left home, whereas those who reported an increase in paternal attention increased in their math interest from the year before $(M=2.27, S D=1.21)$ to the year following $(M=2.58, S D=1.18 ; d=.25)$ their older sibling's departure. No other effects emerged.

For interest in language arts (Table 3), a significant time $\times$ maternal companionship change effect emerged, $F(1,103)=5.80, p<.05$ (Figure 3): Consistent with predictions, youth who did not report an increase in maternal companionship decreased in their interest in language arts from the year before $(M=2.45, S D=1.22)$ to the year after $(M=2.29, S D=1.07 ; d=.14)$ their older sibling's departure, but those who reported an increase in maternal companionship exhibited an increase in interest in language arts from the year prior $(M=2.26, S D=1.17)$ to the year after $(M=2.49, S D=1.03 ; d=.22)$ their older sibling left home. A between-groups effect of gender also emerged, $F(1$, $103)=25.73, p<.001$, such that girls $(M=2.78, S D=1.08)$ reported greater interest than boys $(M=1.96, S D=1.15 ; d=.74)$.

\section{DISCUSSION}

Resource dilution tenets hold that family resources are finite and that, as a natural consequence, the more offspring that parents have, the more thinly family resources will be 


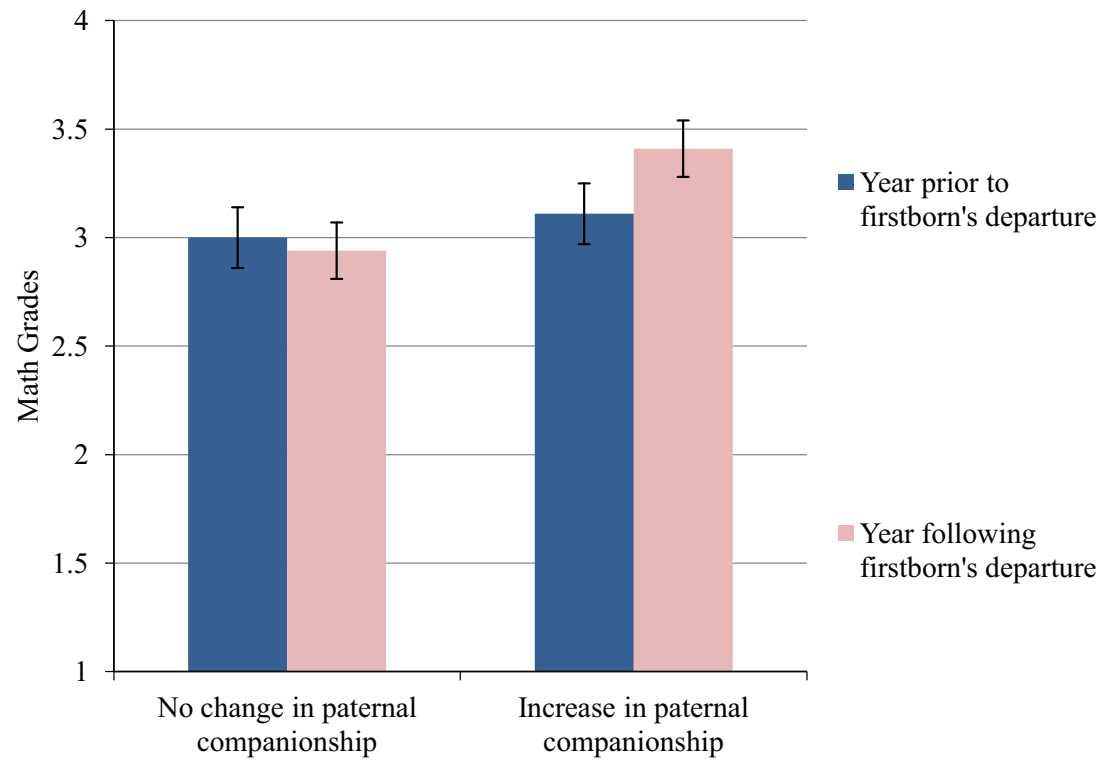

FiguRE 1. Math grades of secondborns before and after firstborns' departure as a function of reported increases in paternal companionship $(n=115)$. Error bars represent the standard error. Math grades for those who received an increase in paternal companionship differed from all other means at $p<.05$, and there were no other significant differences.

distributed among their children. In this way, resource dilution theory implicitly highlights the significant-if indirect-role that siblings play in one another's family experiences and development. In this study, we took advantage of a "natural experiment" in family life brought about by one sibling's development-firstborns' leaving home after high school-to examine secondborn siblings' perceptions of changes in family resources, and whether such changes were linked to increases in secondborns' academic functioning. Our findings were consistent with resource dilution theory in showing that having one fewer sibling in the household-because a firstborn left home-was linked to secondborns' reports of increases in relational resources for a third to half of youth and to increases in access to material resources for about a quarter of these youth. Further, resource increases, particularly increases in companionship and attention, were linked to increases in youths' academic functioning from one school year to the next. In other words, at least from the perspective of youth, the allocation of family resources changed as a function of the number of siblings in the household, and these changes, in turn, had positive implications for youth's academic functioning.

\section{The Allocation of Resources}

Consistent with our expectations, most youth reported an increase in at least some resources in the year after their older sibling left home. The finding that most youth reported an increase in at least one family resource type provides support for resource dilution theory (and family systems theory, more broadly) because changes in resources occurred relatively quickly in the face of family patterns established over the lives of these youth. Additionally, our focus on within-family change limited the influence of unobserved selection effects that may account for the allocation of family resources. In addition to supporting resource dilution theory, our results are consistent with research on the transition to siblinghood (Lasko, 1954; Strohschein et al., 2008; Volling, 2012), in showing that sib- 
TABLE 3

Repeated-measures Analysis of Covariance for Between- and Within-person Effects for Two Models, Youths' Interest in Math ( $=115)$ and Interest in Language Arts $(\mathrm{n}=115)$

\begin{tabular}{|c|c|c|c|c|}
\hline \multirow[b]{2}{*}{ Source } & \multicolumn{2}{|c|}{ Math interest } & \multicolumn{2}{|c|}{ Language arts interest } \\
\hline & Mean square & $F$ value & Mean square & $F$ value \\
\hline \multicolumn{5}{|l|}{ Between-person effects } \\
\hline Gender & 1.99 & 1.27 & 37.00 & $25.73^{* * *}$ \\
\hline Age & .76 & .48 & .92 & .64 \\
\hline Mother education & 1.89 & 1.20 & .99 & .69 \\
\hline Father education & 5.66 & 3.60 & .51 & .35 \\
\hline Sibship size & .08 & .05 & .01 & .00 \\
\hline Mother companionship & .19 & .12 & .00 & .00 \\
\hline Mother attention & 3.25 & 2.06 & 1.46 & 1.01 \\
\hline Father companionship & .24 & .15 & .43 & .30 \\
\hline Father attention & .48 & .31 & .91 & .64 \\
\hline Material goods & .46 & .29 & .86 & .60 \\
\hline Error & 1.57 & & 1.44 & \\
\hline \multicolumn{5}{|l|}{ Within-person effects } \\
\hline Time & .18 & .43 & .98 & 3.37 \\
\hline Time $\times$ Gender & 1.15 & 2.78 & .08 & .29 \\
\hline Time $\times$ Age & .04 & .09 & 1.41 & $4.86^{*}$ \\
\hline Time $\times$ Mother education & .18 & .44 & .97 & 3.34 \\
\hline Time $\times$ Father education & .02 & .04 & .02 & .08 \\
\hline Time $\times$ Sibship size & .53 & 1.28 & .00 & .00 \\
\hline Time $\times$ Mother companionship & .64 & 1.54 & 1.68 & $5.80 *$ \\
\hline Time $\times$ Mother attention & .91 & 2.22 & .67 & 2.30 \\
\hline Time $\times$ Father companionship & .10 & .25 & .28 & .96 \\
\hline Time $\times$ Father attention & 1.75 & $4.26^{*}$ & .58 & 2.01 \\
\hline Time $\times$ Material goods & .01 & .02 & .21 & .71 \\
\hline Error & .41 & & .29 & \\
\hline
\end{tabular}

${ }^{*} p<.05 ; * * p<.01 ; * * * p<.001$.

ship size changes have implications for changes in youths' family resources. In the early stages of family life, when sibship size increases with the birth of another child, family resources allocated to any given child diminish, but later on, when sibship size effectively decreases, resources that are available in everyday family life may be reallocated, such that youth's share of those resources increases.

Importantly, although firstborns' leaving home in some ways constitutes a decrease in sibship size, firstborns remain members of their families, and it is likely that some family resources are still being funneled to the departed sibling (Arnett, 2007). In this study, however, we focused on family resources that were visible to youth and available in everyday family life. Other types of resources, such as financial support, may be less likely to be reallocated to younger siblings when the firstborn leaves home-or in fact may represent an increase in allocation to the firstborn, such as when family income is spent on college tuition or other supports for establishing independence in young adulthood. Although qualitative data such as ours are critical in the early stages of understanding a phenomenon (Camic, Rhodes, \& Yardley, 2003; Watkins, 2012) and are useful in understanding secondborns' perceptions, future work will need to incorporate quantitative measures of family resources before and after a change in sibship/household size to capture changes that the youth in our study may not have spontaneously reported and to address whether perceptions are more important than more objective measures of resource change or vice versa. 


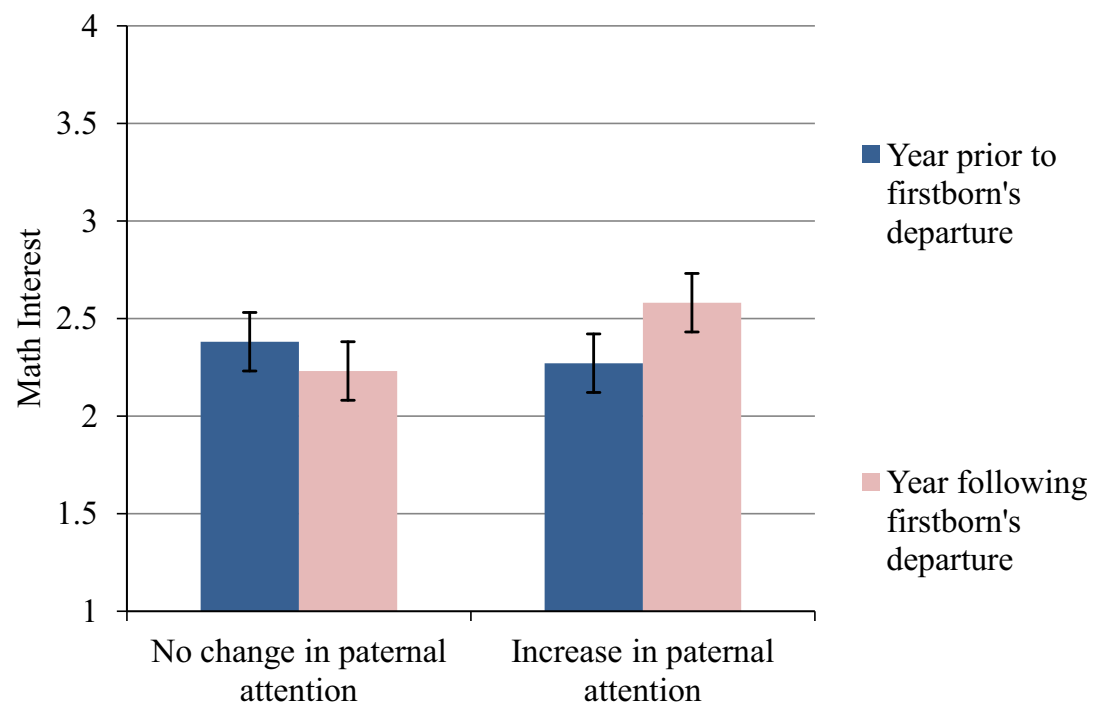

FiguRE 2. Reported math interest of secondborns in the year prior and the year following the firstborn's departure as a function of reported increases in paternal attention $(n=115)$. Error bars represent the standard error. No means were significantly different at $p<.05$.

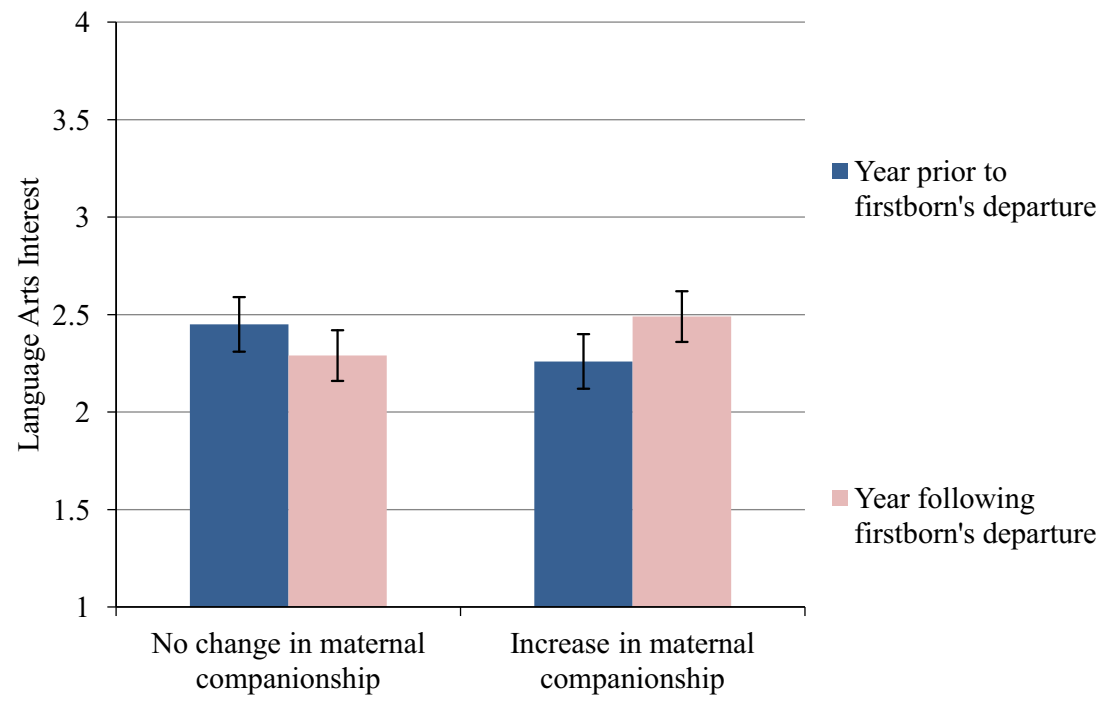

FIGURE 3. Reported language arts interest of secondborns in the year prior and the year following the firstborn's departure as a function of reported increases in maternal companionship $(n=115)$.

Error bars represent the standard error. No means were significantly different at $p<.05$.

\section{Implications of Changing Family Resources}

Rooted in a resource dilution framework, we expected that increases in resources would be associated with improvements in youth school grades and in their academic interests. Consistent with these expectations, increases in paternal companionship were linked to increases in math grades and increases in paternal attention were linked to increases in math interests. In prior research, math has been described as a 
stereotypically masculine domain of interest and achievement (Gunderson, Ramirez, Levine, \& Beilock, 2012), which may explain why fathers' but not mothers' companionship and attention were linked to increases in youth grades and interests in math. For example, fathers may have less anxiety about math competencies and also may encourage their children in this domain due to their own interests (Gunderson et al., 2012). These findings are particularly important given normative declines over time in youth's school grades (Barber \& Olsen, 2004; Dotterer, Lowe, \& McHale, 2014; Dotterer et al., 2009). In contrast, the grades of secondborns who reported an increase in companionship with their father improved, on average, from a B to a B+. Notably, because these analyses were limited to youth who took a math class during both the years before and after their sibling left home, this finding is not due to youth who perform poorly in math dropping out of the math curriculum. In fact, because of the structuring of math courses during the high school years, many of these secondborns may have actually been taking more difficult classes, but still exhibited better grades when they perceived their fathers' companionship as having increased.

Beyond the effects on math grades, our analyses also revealed several findings on the effects of perceived increases in family resources and youth's academic interest in both math and language arts. Past work reveals declines in academic interests across adolescence (Dotterer et al., 2009; Eccles, Wigfield, \& Schiefele, 1998), and youth in this study who did not report increases in parental involvement displayed this pattern of change. Our findings, however, revealed that secondborns who reported an increase in paternal attention exhibited increases in their interest in math and that those who reported an increase in maternal companionship exhibited an increase in their interest in language arts. As noted, math has been shown to be a stereotypically masculine domain (Gunderson et al., 2012); this same line of research suggests that the language arts are stereotypically feminine (Eccles, Wigfield, Harold, \& Blumenfeld, 1993). Together, these patterns may explain why paternal resources were linked to math performance and interest, and maternal resources, to interest in language arts. Importantly, the findings from this "natural experiment" in family life suggest that normative declines in youth's academic interests are not inevitable and that changes in the allocation of family resources may be able to stem or even reverse this pattern.

These findings also suggest that the implications of parental attention may differ from those of companionship; increases in companionship with fathers were linked to math grades, and increases in attention from fathers were linked to math interests. Companionship denoted spending more time together, and in the process of that shared time fathers may have engaged in activities such as helping with math homework, building activities that require measurement and spatial skills, or other activities that foster math skills. Attention, however, does not necessarily imply shared time and thus may be less influential in performance. Instead, increased paternal attention may have promoted youth's focus on the stereotypically masculine - such as math (Gunderson et al., 2012). Given that this pattern did not emerge for mothers, additional research is needed to investigate these domains of parental involvement and their effects.

\section{CONCLUSIONS}

In the face of its contributions to understanding the role of siblings in family resource allocations and youth academic achievement, several limitations of this study suggest directions for future research. First, this study was limited by the size and characteristics of the sample. Because the sample consisted of Caucasian, intact, and primarily dual-earner middle-class American families, these results are only generalizable to those 
of similar economic and cultural backgrounds. For example, although dual-earner families may be unique in that time and attention from parents may be more limited as they balance work and family roles, the distribution of parental resources may be especially important in other family contexts where resources may be even more constrained (e.g., singleparent families). Further, a normative experience for youth from dual-earner middle-class families is college attendance (National Center for Educational Statistics, 2008). Indeed, the vast majority of older siblings in this sample entered college. The typical reasons for firstborns leaving home, however, may vary as a function of a range of sociocultural factors, and those reasons for leaving home may have implications for the redistribution of family resources. Indeed, past work highlights that resource dilution principles differ from one culture to another (Downey, 2001) and from one country to another (Buchmann, 2000; Maralani, 2008; Park, 2008). Future work will need to employ similar within-person designs in these diverse contexts to understand how changes in allocation of resources impact youth of varying circumstances, from diverse ethnic and socioeconomic groups both in and outside the United States.

Second, although our analyses included information about resources provided from mothers and fathers separately, differences in parents' allocation were not explicitly examined. Given the gendered nature of parents' treatment of offspring (e.g., McHale, Updegraff, Jackson-Newsom, Tucker, \& Crouter, 2000), future research with larger samples would benefit from investigating whether parents' allocation of resources is dependent upon their gender as well as the gender and gender composition of their offspring. For example, it is possible that mothers and fathers may become even more involved with same-gendered offspring (i.e., mothers with daughters, fathers with sons) following the departure of an older sibling.

Third, our assessment of changes in family resources was limited to qualitative data collected at one point in time. Although the categories of resources we studied were grounded in prior research (Downey, 1995), they may not have fully captured the changes in resources that secondborns experienced. In particular, our open-ended questions may have inclined participants to report on changes in relational resources than in material resources. Other resources such as financial supports and status within the family may change as a function of sibling transitions and may play a role in youth's academic functioning. Future studies should measure a wider variety of resources as well as use quantitative assessments collected over time for more objective assessments of changes in youth's resources. Additionally, although we obtained information about school grades from report cards, we used reports by secondborns of both changes in their family resources and their levels of interest in math and language arts. The latter associations may be inflated by mono-reporter biases, underscoring the importance of obtaining information from multiple sources in future studies.

Notwithstanding these limitations, the current study contributes to the literature in several ways. Past work reveals that youth with more siblings receive fewer resources (Downey, 1995; Lasko, 1954; Strohschein et al., 2008), and other studies show that those with more siblings exhibit poorer academic functioning (Blake, 1989; Downey, 2001; Steelman et al., 2002) as compared to youth from smaller families. Most of these studies, however, employed between-family and cross-sectional comparisons-which fail to account for third variable or selection effects that might otherwise explain observed associations. In contrast, this study used longitudinal, within-person comparisons to examine links between youth's perceptions of changes in family resources and changes in their academic functioning following their siblings' departure from the family home. This focus on change provides for a contribution to the literature in documenting the significance of sibship size in youth's daily experiences and academic functioning. Furthermore, our findings add to the literature on the continuing significance of youth's experiences with parents across 
adolescence. Although declines in academic functioning are normative during this developmental period (Barber \& Olsen, 2004; Dotterer et al., 2009; Eccles et al., 1998), our findings add to others in showing that parents' role remains important, and that their companionship and attention have the power to stem or even reverse those declines. Importantly, these effects emerged despite low power in our sample that may have hindered the ability to detect significant differences. The results imply that parents, teachers, and school counselors seeking to stem declines in adolescents' academic interests and performance should focus on family relational resources. Finally, our findings speak to the importance of one family influence on youth development that has been relatively neglected in the family literature - siblings - who, even when they are absent, can have an impact on their sisters and brothers.

\section{REFERENCES}

Arnett, J. (2007). Emerging adulthood: What is it, and what is it good for? Child Development Perspectives, 1, 6873. doi:10.1111/j.1750-8606.2007.00016.x.

Barber, B. K., \& Olsen, J. A. (2004). Assessing the transitions to middle and high school. Journal of Adolescent Research, 19, 3-30. doi:10.1177/0743558403258113.

Behrman, J. R., Pollak, R. A., \& Taubman, P. (1989). Family resources, family size, and access to financing for college education. Journal of Political Economy, 97, 398-419.

Berbaum, M. L., \& Moreland, R. L. (1980). Intellectual development within the family: A new application of the confluence model. Developmental Psychology, 16, 500-515. doi:10.1037/0012-1649.16.5.506 515.

Blake, J. (1989). Sibship size and achievement. Berkeley: University of California Press.

Buchmann, C. (2000). Family structure, parental perceptions, and child labor in Kenya: What factors determine who is enrolled in school? Social Forces, 78, 1349-1379. doi:10.2307/3006177.

Camic, P. M., Rhodes, J. E., \& Yardley, L. (2003). Qualitative research in psychology: Expanding perspectives in methodology and design. Washington, DC: American Psychological Association.

Christenson, S. L., Rounds, T., \& Gorney, D. (1992). Family factors and student achievement: An avenue to increase students' success. School Psychology Quarterly, 7, 178-206. doi:10.1037/h0088259.

Cohen, J. (1988). Statistical power analysis for the behavioral sciences. San Diego, CA: Academic Press.

Coleman, J. S. (1988). Social capital in the creation of human capital. American Journal of Sociology, 94, S95S120.

Conley, D., Pfeiffer, K. M., \& Velez, M. (2007). Explaining sibling differences in achievement and behavioral outcomes: The importance of within- and between-family factors. Social Science Research, 36, 1087-1104.

Davis-Kean, P. E. (2005). The influence of parent education and family income on child achievement: The indirect role of parental expectations and the home environment. Journal of Family Psychology, 19, $294-304$. doi:10.1037/0893-3200.19.2.294.

Dotterer, A. M., Lowe, K., \& McHale, S. M. (2014). Academic growth trajectories and family relationships among African American youth. Journal of Research on Adolescence, 24, 734-747. doi:10.1111/jora.12080.

Dotterer, A. M., McHale, S. M., \& Crouter, A. C. (2009). The development and correlates of academic interests from childhood through adolescence. Journal of Educational Psychology, 101, 509-519. doi:10.1037/ a0013987.

Downey, D. B. (1995). When bigger is not better: Family size, parental resources, and children's educational performance. American Sociological Review, 60, 746-761. doi:10.2307/2096320.

Downey, D. B. (2001). Number of siblings and intellectual development: The resource dilution explanation. American Psychologist, 56(6-7), 497-504. doi:10.1037/0003-066X.56.6-7.497.

Eccles, J., Wigfield, A., Harold, R. D., \& Blumenfeld, P. (1993). Age and gender differences in children's self- and task perceptions during elementary school. Child Development, 64, 830-847. doi:10.2307/1131221.

Eccles, J., Wigfield, A., \& Schiefele, U. (1998). Motivation to succeed. In W. Damon (Series Ed.) \& N. Eisenberg (Vol. Ed.), Handbook of child psychology: Vol. 3. Social, emotional, and personality development (5th ed., pp. 1017-1095). New York: Wiley.

Ernst, C., \& Angst, J. (1983). Birth order: Its influence on personality. Berlin: Springer-Verlag.

Gottlieb, L. N., \& Mendelson, M. J. (1990). Parental support and firstborn girls' adaptation to the birth of a sibling. Journal of Applied Developmental Psychology, 11, 29-48. doi:10.1016/0193-3973(90)90030-N.

Gunderson, E. A., Ramirez, G., Levine, S. C., \& Beilock, S. L. (2012). The role of parents and teachers in the development of gender-related math attitudes. Sex Roles, 66, 153-166. doi:10.1007/s11199-011-9996-2. 
Huston, T. L., McHale, S. M., \& Crouter, A. C. (1985). Changes in the marital relationship during the first year of marriage. In R. Gilmour \& S. Duck (Eds.), The emerging field of personal relationships (pp. 109-132). Hillsdale, NJ: Erlbaum.

Kendrick, C., \& Dunn, J. (1980). Caring for a second baby: Effects on interaction between mother and firstborn. Developmental Psychology, 16, 303-311. doi:10.1037/0012-1649.16.4.303.

Lasko, J. (1954). Parent behavior toward first and second children. Genetic Psychology Monographs, 4, 98-137.

Lawson, D. W., \& Mace, R. (2008). Sibling configuration and childhood growth in contemporary British families. International Journal of Epidemiology, 37, 1408-1421. doi:10.1093/ije/dyn116.

Maralani, V. (2008). The changing relationship between family size and educational attainment over the course of socioeconomic development: Evidence from Indonesia. Demography, 45, 693-717.

McHale, S. M., Updegraff, K. A., Jackson-Newsom, J., Tucker, C. J., \& Crouter, A. C. (2000). When does parents' differential treatment have negative implications for siblings? Social Development, 9, 149-172. doi:10.1111/ 1467-9507.00117.

National Center for Educational Statistics (2008). Digest of Education Statistics, 2007, Table 192. College enrollment and enrollment rates of recent high school completers, by sex: 1960-2006. Washington, DC: U.S. Department of Education.

Okagaki, L., \& Frensch, P. A. (1998). Parenting and children's school achievement: A multiethnic perspective. American Educational Research Journal, 35, 123-144. doi:10.2307/1163454.

Park, H. (2008). Public policy and the effect of sibship size on educational achievement: A comparative study of 20 countries. Social Science Research, 37, 874-887. doi:10.1016/j.ssresearch.2008.03.002.

Parker, F., Boak, A. Y., Griffin, K. W., Ripple, C., \& Peay, L. (1999). Parent-child relationship, home learning environment, and school readiness. School Psychology Review, 28, 413-425.

Raley, S., \& Bianchi, S. (2006). Sons, daughters, and family processes: Does gender of children matter? Annual Review of Sociology, 32, 401-421. doi:10.1146/annurev.soc.32.061604.123106.

Retherford, R. D., \& Sewell, W. H. (1989). How intelligence affects fertility. Intelligence, 13, 169-185. doi:10.1016/ 0160-2896(89)90015-9.

Rodgers, J., Cleveland, H., van den Oord, E., \& Rowe, D. C. (2000). Resolving the debate over birth order, family size, and intelligence. American Psychologist, 55, 599-612. doi:10.1037/0003-066X.55.6.599.

Steelman, L., Powell, B., Werum, R., \& Carter, S. (2002). Reconsidering the effects of sibling configuration: Recent advances and challenges. Annual Review of Sociology, 28, 243-269. doi:10.1146/annurev. soc.28.111301.093304.

Stewart, R. (1990). The second child: Family transition and adjustment. Thousand Oaks, CA: Sage Publications.

Strohschein, L., Gauthier, A. H., Campbell, R., \& Kleparchuk, C. (2008). Parenting as a dynamic process: A test of the resource dilution hypothesis. Journal of Marriage and Family, 70, 670-683. doi:10.1111/j.17413737.2008.00513.x.

United States Census Bureau (2015). Pennsylvania quick facts. Retrieved from http://quickfacts.census.gov/qfd/ states/42000.html

Volling, B. L. (2012). Family transitions following the birth of a sibling: An empirical review of changes in the firstborn's adjustment. Psychological Bulletin, 138, 497-528. doi:10.1037/a0026921.

Watkins, D. C. (2012). Qualitative research: The importance of conducting research that doesn't "count". Health Promotion Practice, 13, 153-158. doi:10.1177/1524839912437370.

Whiteman, S. D., McHale, S. M., \& Crouter, A. C. (2011). Family relationships from adolescence to early adulthood: Changes in the family system following firstborns' leaving home. Journal of Research on Adolescence, 21, 461-474. doi:10.1111/j.1532-7795.2010.00683.x.

Fam. Proc., Vol. x, xxxx, 2015 